\title{
Aplicação de um Sistema Imunológico Artificial em um Tower Defense
}

\author{
Renato de Pontes Pereira \\ UNIVEM, Centro Universitário Eurípedes de Marília, Computing and \\ Information Systems Research Lab, \\ renato.ppontes@gmail.com \\ Mauricio Duarte \\ UNIVEM, Centro Universitário Eurípedes de Marília, Computing \\ and Information Systems Research Lab, \\ maur.duarte@gmail.com
}

\begin{abstract}
Resumo: Um dos problemas enfrentados na criação da inteligência artificial em um jogo é a resposta mecânica e desequilibrada do computador às ações do jogador. Diversas técnicas podem ser usadas para evitar ou amenizar isso. Por exemplo, com técnicas bioinspiradas como redes neurais artificiais, algoritmos genéticos ou sistemas imunológicos artificiais. Esse artigo apresenta a área de sistemas imunológicos artificiais, uma demonstração da aplicação dessa técnica em um jogo de Tower Defense.
\end{abstract}

Palavras-Chave: Sistemas Imunológicos Artificiais. Inteligência Artificial. Jogos. Tower Defense.

\section{Application of an Artificial Immune System in aTower Defense}

\begin{abstract}
One of the problems faced when creating the artificial intelligence in a game is the mechanic and unbalanced answers from the computer to the player's actions. Several techniques can be applied to avoid or mitigate it, e.g., with bio-inspired techniques, such as artificial neural networks, genetic algorithms or artificial immune systems. This paper aims to introduce the field of artificial immune systems, evidencing the application of such technique in Tower Defense games.
\end{abstract}

Keywords: Artificial Immune Systems. Artificial Intelligence. Games. Tower Defense 


\section{Introdução}

Os jogos aumentam a imersão dos jogadores de várias formas, seja por gráficos realistas, histórias bem planejadas ou uma boa ambientação. Nesse contexto, outro aspecto importante a ser considerado é o do desenvolvimento da inteligência artificial (IA).

A IA está presente nos jogos desde o nascimento dos videogames em 1970, e são aplicadas em diversos estilos e ambientes, desde os mais simples jogos como jogos da velha até aqueles de representação complexa, como os de simulação de voo ou de tiro em primeira pessoa, que usam táticas de combate real. (Rabin 2002) (Charles 2007).

Em muitos casos, a complexidade dos ambientes torna o uso de algumas técnicas clássicas de inteligência artificial impraticável, em outros o desequilíbrio entre as ações do computador e a habilidade do jogador é muito grande. Esses são alguns dos motivos pelos quais o jogo não causa a imersão desejada e o jogador acaba desestimulado a continuar. (Rabin 2002) (Bourg e Seemann 2004).

Diversas técnicas têm sido aplicadas na tentativa de suprir a necessidade de representar melhor ambientes complexos e de responder de forma mais natural às ações do jogador. Por exemplo, técnicas bio-inspiradas, árvores de comportamento ou algoritmos de aprendizado. As técnicas bio-inspiradas possuem características interessantes que se enquadram nesse contexto, o que possibilita a geração de um comportamento mais natural e um grande nível de abstração para tratar de problemas complexos. (Bourg e Seemann 2004) (Charles 2007).

A inteligência artificial bio-inspirada é o subcampo da IA que explora as vantagens e propriedades de sistemas naturais. Algumas técnicas já são usadas em jogos com bastante aceitação, como as redes neurais artificiais, vida artificial ou algoritmos genéticos. Outras como os sistemas imunológicos artificiais (SIA) têm emergido nos últimos anos em aplicações nas mais diversas áreas, inclusive em jogos de computadores (Bourg e Seemann 2004).

Este artigo tem como objetivo demonstrar a aplicabilidade dos sistemas imunológicos artificiais em jogos, e visa obter, principalmente, um comportamento mais natural e equilibrado nas ações do computador. As Seções 2 e 3 apresentam a base teórica, e apontam três processos e técnicas básicas dos sistemas imunes biológicos e artificiais. A Seção 4 descreve o Tower Defense, que será usado como estudo de caso, e as Seções 5 e 6 apresentam os resultados das simulações realizadas e na discussão.

\section{Sistema Imunológico Biológico}

O sistema imunológico é um complexo conjunto de tecidos, células e moléculas que trabalham de forma coordenada para defender o organismo de ataques de invasores (conhecidos como patógenos). Pode ser dividido basicamente em dois subssistemas inter-relacionados: o imunológico inato e o imunológico adaptativo (também chamados de imunidade natural ou nativa e imunidade 
adquirida ou específica, respectivamente). Os dois sistemas trabalham de formas distintas, mas tentam atingir o mesmo objetivo: proteger o organismo. (Abbas, Lichtman e Pillai 2007) (Abbas e Lichtman 2008) (Castro e Zuben 1999).

O sistema inato é a primeira linha de defesa contra os invasores: sempre está presente em um indivíduo saudável, protegendo-lhe o corpo desde seu nascimento. Esse sistema é composto por mecanismos de defesa celulares e bioquímicos, os quais respondem rapidamente à infecções, e podem destruir os patógenos ao no primeiro encontro. Apesar de ser indispensável para o organismo, o sistema inato não pode se adaptar a novos patógenos ou a suas novas mutações. (Abbas, Lichtman e Pillai 2007) (Abbas e Lichtman 2008) (Castro e Zuben 1999).

O sistema imunológico adaptativo tem a função de identificar e eliminar os invasores que conseguem passar pelo sistema inato. Se desenvolve com o tempo, aprendendo e se adaptando à cada nova infecção. Outra característica muito importante nesse sistema é a capacidade de se lembrar de patógenos, conseguindo responder-lhes de forma mais eficaz, quando encontrados novamente. (Abbas, Lichtman e Pillai 2007) (Abbas e Lichtman 2008).

As duas células mais importantes para o processo de detecção e eliminação de invasores são dois tipos de leucócitos chamados de linfócitos T e linfócitos B (ou células T e B). Essas células possuem receptores que são responsáveis por detectar as células estrangeiras. Qualquer molécula identificada pelos receptores é chamada de antígeno e é considerada como invasora pelo sistema imune. (Aickelin e Dasgupta 2006).

A principal função das células $\mathrm{B}$ é a produção de anticorpos como resposta aos patógenos. Cada linfócito B produz um tipo único de anticorpo e cada anticorpo pode reconhecer apenas um tipo de antígeno. As células $\mathrm{T}$ diferem das células B por possuírem um receptor especial (TCR) em sua superfície, e com o qual se identificam pequenos fragmentos de antígenos na superfície de células infectadas ou cancerígenas (Castro e Timmis 2002) (Abbas, Lichtman e Pillai 2007) (Castro e Zuben 1999).

\subsection{Seleção Clonal}

Quando um patógeno é reconhecido, o sistema imune deve ter a quantidade necessária de células defensoras com a mesma afinidade para eliminá-lo, mas em um estado inicial o número de linfócitos capazes de identificar o mesmo antígeno é limitado. O sistema imunológico precisa ter um processo que consiga suprir essa demanda de forma rápida e efetiva. Esse processo é chamado de seleção clonal. A teoria da seleção clonal estabelece a ideia de que somente as células que reconhecem os antígenos proliferam, e, dessa forma, alcançam a quantidade mínima necessária para eliminar os patógenos identificados. A seleção clonal atua tanto com células $B$ quanto células $T$. (Castro e Zuben 1999) (Castro e Timmis 2002). 


\subsection{Seleção Positiva}

Durante o processo de criação dos linfócitos B e T algumas células podem não se desenvolver (não adquirir receptores) ou não conseguir adquirir uma capacidade mínima para o reconhecimento de antígenos (receptores não produtivos para o organismo). O processo de seleção positiva serve para evitar o acúmulo desses linfócitos, selecionando apenas células produtivas e úteis para o corpo. Nessa seleção são apresentadas diversas células aos novos linfócitos, e se estes não reconhecerem nenhuma célula do conjunto, serão descartados. (Castro e Timmis 2002) (Abbas, Lichtman e Pillai 2007).

\subsection{Seleção Negativa}

No processo de seleção negativa acontece o inverso: se os linfócitos reconhecem antígenos próprios, são descartados. Essa característica de não assimilar células próprias como as invasoras são chamadas de tolerância imunológica e é definida no desenvolvimento dos linfócitos. No processo são apresentados milhares de células próprias para os linfócitos. Se algum deles ligar a uma célula apresentada, o encontro ativa um mecanismo de autodestruição e o linfócito morre. (AISWeb 2010).

\section{Sistema Imunológico Artificial}

Esse sistema possui diversas características importantes do ponto de vista de jogos de computadores, como reconhecimento de padrões, detecção de anomalias, tolerância a ruído, a falhas, autonomia, aprendizado, memória, autoorganização etc. É um sistema natural com um conjunto de funcionalidades diversificadas e poderosas que trabalha ao mesmo tempo, propriedade estas dificilmente encontrada em outros sistemas biológicos. (Castro e Timmis 2002).

Sistema Imunológico Artificial (SIA), como o próprio nome sugere, é um modelo computacional inspirado no funcionamento do sistema imune biológico e pode ser usado em diversas aplicações, como por exemplo, em problemas de reconhecimento de padrões, detecção de falhas, detecção e eliminação de vírus, detecção de intrusão, entre outras. (Dasgupta 2006).

Existem diversos algoritmos baseados nesse sistema. São de vários níveis de complexidade e exploram características diferentes no sistema imune biológico. Neste artigo serão abordados três dos algoritmos mais simples e conhecidos, inspirados nos processos citados anteriormente.

\subsection{Seleção Negativa}

No contexto biológico, a seleção negativa é responsável por remover os linfócitos que reagem à moléculas do próprio organismo, acontece no desenvolvimento dessas células, antes de saírem pelo corpo. Esse processo garante que os linfócitos percorram o organismo sem causar ativações falsas no sistema imune. (AISWeb 2010) (Castro e Timmis 2002). 
O algoritmo de seleção negativa é inspirado nesse mecanismo biológico, e é um dos primeiros modelos de SIA, proposto pela primeira vez em (Forrest et al 1994), para detecção de mudança de dados causada por vírus no campo de segurança computacional. Esse modelo é um dos métodos de detecção de recursos próprios e não próprios. (AISWeb 2010) (Castro e Timmis 2002) (Dasgupta 2006)

De forma simplificada o algoritmo (Figura 1) apresenta elementos que fazem parte do conjunto do sistema para detectores gerados aleatoriamente, e se reconhecem esses elementos, são eliminados. Os que sobram do processo formam o conjunto final de receptores prontos para serem usados.

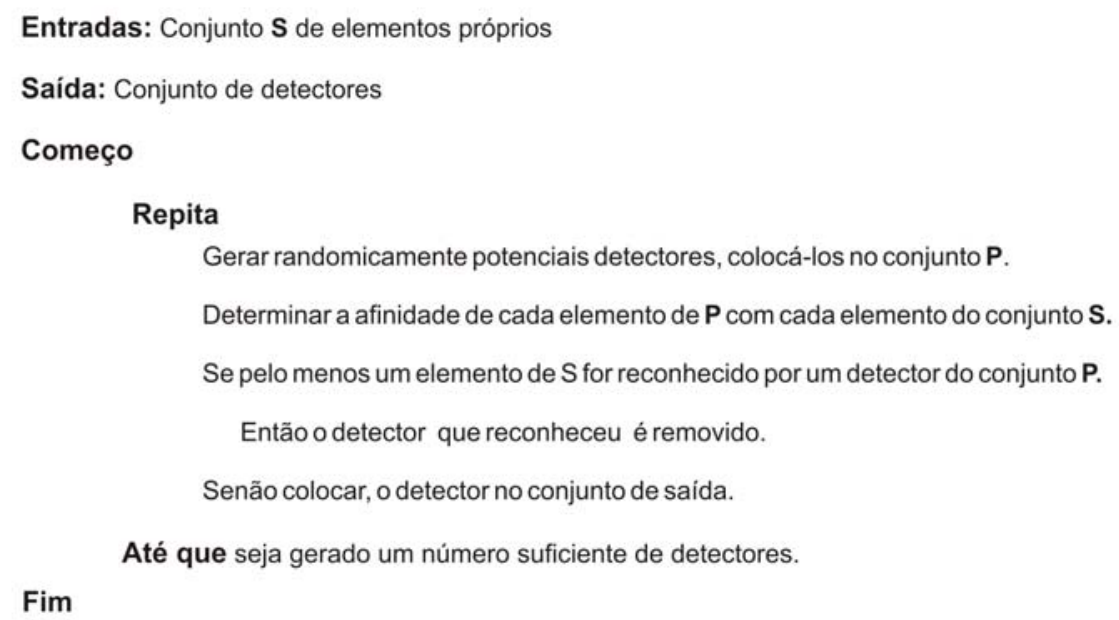

Figura 1. Algoritmo de seleção negativa [AISWeb 2010].

\subsection{Seleção Positiva}

No processo biológico da seleção positiva, somente os linfócitos que reconhecem algumas moléculas próprias especiais recebem permissão para percorrer o corpo, enquanto as outras são descartadas. Esse mecanismo faz com que células com pouco desempenho não finalizem seu desenvolvimento, e deixem espaço e recursos para células mais úteis. (Castro e Timmis 2002).

Esse algoritmo (Figura 2) é semelhante ao da seleção negativa: um conjunto de elementos próprios é passado para detectores gerados aleatoriamente; se um detector não reconhecer pelo menos um dos elementos próprios, é descartado. (Castro e Timmis 2002). 
Entradas: Conjunto $\mathbf{S}$ de elementos próprios

Saida: Conjunto de detectores

Começo

Repita

Gerar randomicamente potenciais detectores, colocá-los no conjunto P.

Determinar a afinidade de cada elemento de $\mathbf{P}$ com cada elemento do conjunto $\mathbf{S}$.

Se um detector do conjunto $\mathrm{P}$ não reconhece nenhum elemento do conjunto $S$.

Então o detector é removido.

Senão colocar, o detector no conjunto de saída.

Até que seja gerado um número suficiente de detectores.

Fim

Figura 2. Algoritmo de seleção positiva.

\subsection{Seleção Clonal}

Se um ou mais antígenos são encontrados, o sistema imunológico precisa produzir células suficientes para eliminá-los. Isso acontece por meio do processo de seleção clonal, em que os linfócitos que foram estimulados pelos antígenos são usados como modelos para gerar novas células. Esse mecanismo faz com que as novas células produzidas possuam receptores capazes de identificar os mesmos antígenos.

A seleção clonal é válida tanto para células B quanto células T. A diferença é que as células $B$ podem sofrer uma pequena mutação para aumentar a afinidade com os antígenos reconhecidos e as células T, não. Por causa da adaptabilidade via mutação das células $\mathrm{B}$, os algoritmos clonais geralmente são modelados com base nelas. (Castro e Timmis 2002).

Entre os algoritmos baseados no princípio da seleção clonal o CLONALG se destaca, como um dos mais populares e mais usados. Proposto em [Castro e Zuben 2000a], o algoritmo inicialmente foi desenvolvido para aplicações de reconhecimento de padrões e depois adaptado para resolver tarefas de otimização. (Brownlee 2005) (Castro e Timmis 2002) (AISWeb 2010) (Castro e Zuben 2000a)(Castro e Zuben 2000b).

O algoritmo CLONALG (Figura 3) trabalha com duas populações: a população de antígenos Ag (padrões a serem reconhecidos) e a população de anticorpos P. Depois de uma inicialização aleatória da população $\mathrm{P}$ o algoritmo determina a afinidade dos elementos criados para todos os indivíduos da população Ag, selecionando para clonagem os que tiverem mais afinidade e no final gerando um conjunto de detectores. (Al-Sheshtawi, Abdul-Kader e Ismail 2010) (AISWeb 2010). 
Entradas: Conjunto $\mathbf{S}$ de padrões a serem reconhecidos

Saída: Conjunto de memória capaz de classificar padrões desconhecidos.

\section{Começo}

Criar um conjunto $\mathbf{A}$ de anticorpos gerados aleatoriamente.

Para todos padrões em S.

Determinar a afinidade de cada anticorpo de $\mathbf{A}$.

Gerar clones do subconjunto de anticorpos de A com maiores afinidades.

Fazer a mutação dos atributos dos clone.

Fazer uma cópia dos anticorpos de mais afinidade para o conjunto de memória.

Substituir os anticorpos em A com menor afinidade por outros gerados aleatoriamente.

Fim

Fim

Figura 3. Algoritmo de seleção clonal [AISWeb 2010].

\section{Desenvolvimento de um Tower Defense}

Para demonstrar a aplicabilidade das técnicas de SIA, está sendo desenvolvido um jogo no estilo Tower Defense. Nessa modalidade o jogador deve colocar torres em locais estratégicos do mapa para atacar e evitar que as unidades do inimigo alcancem seu objetivo (normalmente alcançar o final do mapa ou seu ponto específico).

Para que cada elemento tenha características diferentes, as torres e as unidades de ataque possuirão três atributos com valores variáveis. Os atributos das torres são velocidade de ataque, raio de visão e dano por ataque. Para as unidades de ataque os atributos são velocidade de movimentação, capacidade de defesa e quantidade de pontos de vida.

O jogo será dividido em turnos com três fases: manutenção, ação e verificação de resultados. Na primeira fase o jogador de ataque escolhe as unidades que percorrerão o mapa e o de defesa posicionará suas torres. Em seguida entra a fase de ação, em que os jogadores não poderão "atuar", pois esta serve apenas para calcular os combates e mostrar a animação (no caso da implementação visual). Por último, os resultados serão verificados para definir se chegou ao final do jogo ou não. E este terminará quando um dos jogadores alcançar uma quantidade pré-definida de pontos ou se for atingido a quantidade máxima de turnos.

A princípio o desenvolvimento da inteligência artificial ficará apenas para o jogador atacante, que usará um sistema imunológico artificial para selecionar as unidades mais eficazes contra a estratégia escolhida pelo jogador defensor. 


\section{Experimentos Realizados}

As primeiras simulações realizadas usaram apenas seis tipos de unidades (A, B, C, D, E e F), sem considerar seus atributos. Ao usar a ideia da seleção clonal, o jogador artificial seleciona a unidade com maior pontuação para gerar seu clone. Também substitui todas as unidades com pontuação abaixo de um nível mínimo por outras geradas aleatoriamente. Se nenhuma unidade possui uma pontuação abaixo do mínimo esperado, o jogador seleciona a de menor pontuação e a substitui por outra também gerada aleatoriamente.

Na primeira simulação (Figura 4) foram definidas pontuações fixas para cada unidade, sem variar durante o jogo, como se o jogador defensor não fizesse nenhuma mudança em sua estratégia. É possível verificar que inicialmente o atacante só possuía unidades $\mathrm{B}, \mathrm{D}$ e $\mathrm{F}$, sendo que a unidade $\mathrm{D}$ possuía maior pontuação. Aproximadamente, no turno seis, o sistema colocou uma unidade C no jogo e "descobriu" que aquela unidade obteve maior pontuação, assim continuou a ser clonada até o fim, ficando com cerca de 18 dessas unidades atacando.

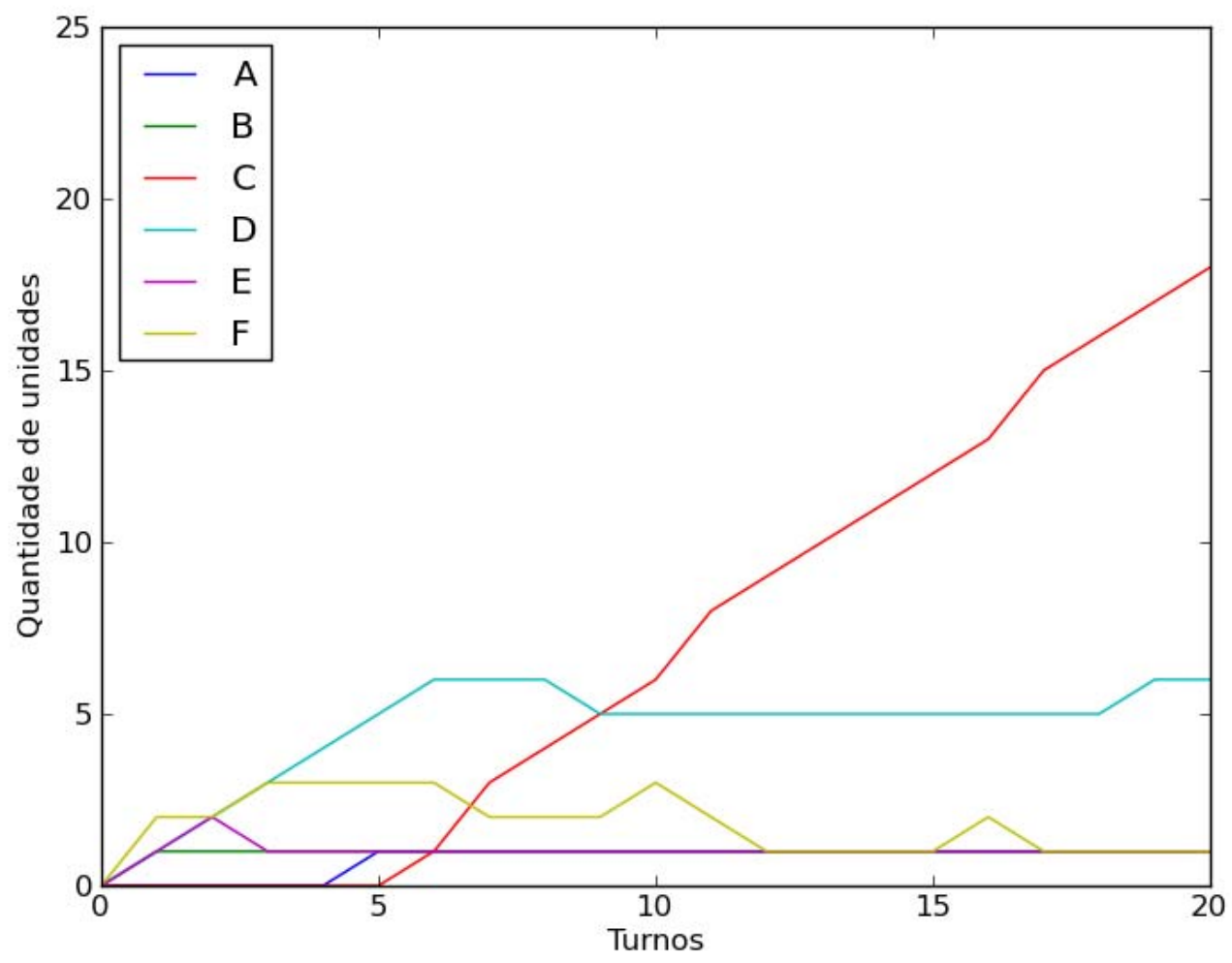

Figura 4. Primeira simulação, usando seis tipos de unidades (A, B, C, D, E e F), começando o jogo com 4 unidades aleatórias, adicionando uma unidade a mais por turno. A quantidade máxima de turnos foi definida como sendo 20 e a quantidade mínima aceitável de pontuação foi 10. 
A segunda simulação (Figura 5) usa os mesmos parâmetros iniciais da primeira simulação, mas no turno 10 a pontuação das unidades muda, simulando uma mudança repentina na estratégia do jogador defensor. Novamente é possível ver que a unidade $C$ possui a maior pontuação até a metade do jogo, mas após a mudança de pontuação a unidade $\mathrm{F}$ teve maior desempenho, sendo clonada até o fim do jogo.

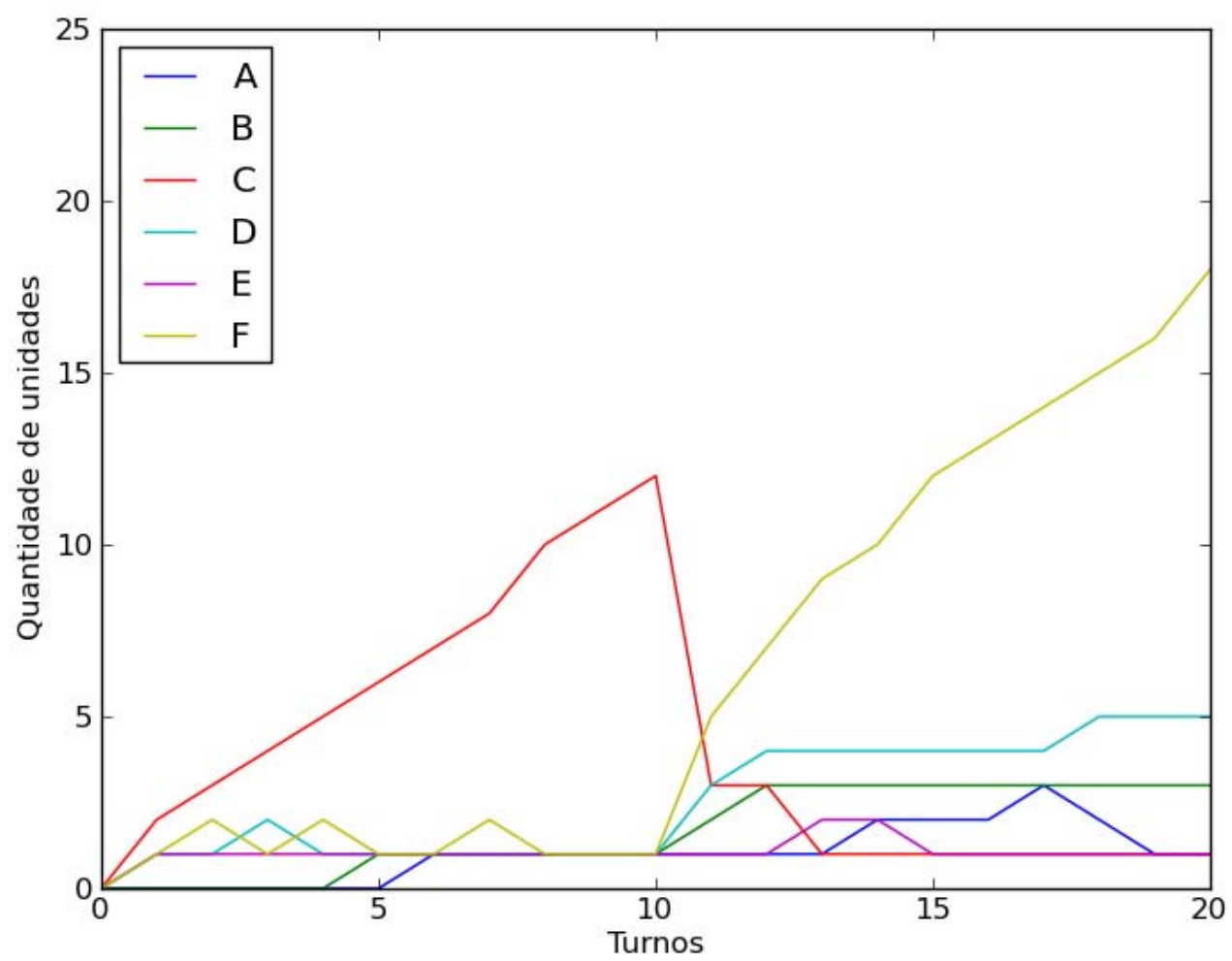

Figura 5. Segunda simulação, usando seis tipos de unidades (A, B, C, D, E e $F)$, começando o jogo com 4 unidades aleatórias e adicionando uma unidade a mais por turno. A quantidade máxima de turnos foi definida como sendo 20 e a quantidade mínima aceitável de pontuação foi 30.

Na terceira simulação os tipos foram retirados e as unidades são diferenciadas por seus atributos: health representando os pontos de vida, defense representando a capacidade de defesa e speed representando a velocidade. A soma dos três atributos deve ser igual a 100. Inicialmente foram utilizadas 20 unidades com os atributos gerados aleatoriamente e a cada turno foram adicionadas duas novas unidades.

Nessa simulação foram definidos três estágios (simulando as mudanças de torres do jogador defensor), sendo que o primeiro acaba no turno 6, o segundo acaba no 12 e o terceiro vai até o final. A Tabela 1 mostra quais são os valores ideais para os atributos em cada estágio do jogo. 
Tabela 1. Valores ideais para os atributos em cada estágio do jogo

\begin{tabular}{|l|c|c|c|}
\hline & $\begin{array}{c}\text { Estágio } \\
\mathbf{1}\end{array}$ & $\begin{array}{c}\text { Estágio } \\
\mathbf{2}\end{array}$ & $\begin{array}{c}\text { Estágio } \\
\mathbf{3}\end{array}$ \\
\hline health & 30 & 15 & 50 \\
\hline defense & 10 & 75 & 30 \\
\hline Speed & 60 & 10 & 20 \\
\hline
\end{tabular}

A Figura 6 mostra a média dos atributos durante o jogo simulado, e é possível observar que o sistema se adapta rapidamente, fazendo o atributo speed sobressair logo no segundo turno. No turno 7 os atributos mudam e o sistema novamente se adapta ao novo cenário, o que faz com que a defesa se sobressaia. No estágio final, ao turno 13, outra mudança ocorre e o sistema se adequa novamente.

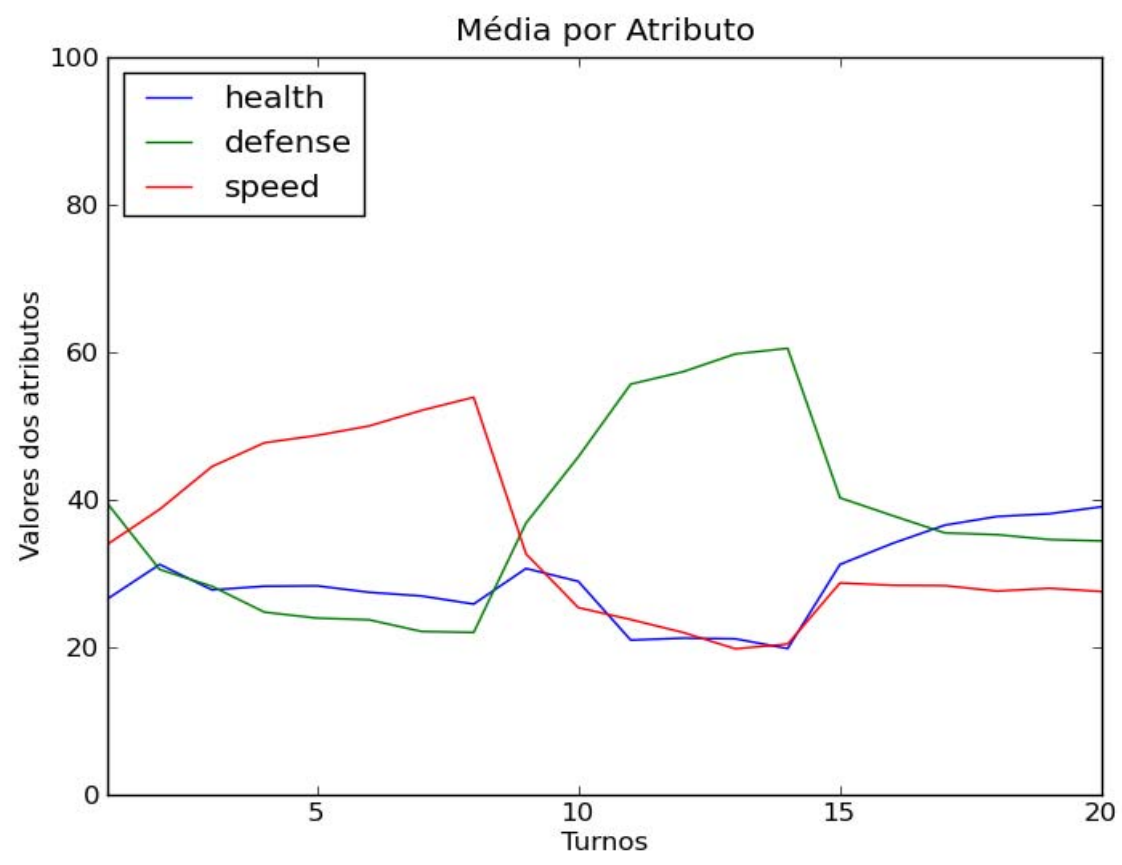

Figura 6. Terceira simulação, média de valores dos atributos. A simulação foi iniciada com 20 unidades e pontuação mínima de 30.

\section{Discussão}

A partir dos dados analisados, pôde-se observar o comportamento adaptativo do sistema imunológico seguindo as mudanças feitas no ambiente. Essa abordagem já elimina o comportamento previsível e mecânico do computador, pois apesar da adaptatividade demonstrada nas simulações, o sistema ainda possui elementos aleatórios que fazem com que todas as partidas tenham diferentes respostas para as mesmas ações. 
Na continuação do projeto, será melhor analisada a questão do desequilíbrio de habilidade entre o jogador e o computador. Também pretende-se desenvolver a parte de interação do jogo para testes com jogadores humanos, além da exploração do mecanismo de memória da seleção clonal para conseguir respostas mais eficientes contra ações já executadas pelo oponente humano. 


\section{Referências}

Abbas A. K. and Lichtman A. H. (2008). Functions and Disorders of the Immune System, Saunders, 3rd edition.

Abbas A. K., Lichtman A. H. and Pillai S. (2007). Cellular and Molecular Immunology, Saunders, 6th edition.

Aickelin, U. and Dasgupta, D. (2006). Artificial Immune Systems, IEEE Computational Intelligence Magazine.

AISWeb (2010). "AISWeb: The Online Home of Artificial Immune Systems", endereço: http://www.artificial-immune-systems.org. Acesso em 17/06/2010.

Al-Sheshtawi, K. A., Abdul-Kader, M. H. and Ismail, N. A. (2010). Artificial Immune Clonal Selection Algorithms: A Comparative Study of CLONALG, opt-IA, and BCA with Numerical Optimization Problems, IJCSNS International Journal of Computer Science and Network Security.

Bourg, D. M. and Seemann, G. (2004). AI for Game Developers, O'Reilly Media, 1st edition.

Brownlee, J. (2005). Clonal Selection Theory \& CLONALG: The Clonal Selection Classification Algorithm (CSCA). Technical Report.

Castro, L. N. and Timmis, J. (2002). Artificial Immune Systems: A New Computational Intelligence Approach, Springer. 1st edition.

Castro, L. N. and Zuben, F. J. (1999). Artificial Immune Systems: Part I - Basic Theory and Applications. Technical Report - DCA 01/99.

Castro, L. N. and Zuben, F. J. (2000a). The Clonal Selection Algorithm with Engineering Applications, GECCO - Workshop Proceedings.

Castro, L. N. and Zuben, F. J. (2000b). An Evolutionary Immune Network For Data Clustering, 6th Brazilian Symposium on Neural Networks.

Charles, D. (2007). Biologically Inspired Artificial Intelligence for Computer Games, Edited by Colin Fyfe, Daniel Livingstone and Stephen Mcglinchey, IGI Publishing, 1st edition.

Dasgupta, D. (2006). Advances in Artificial Immune Systems, IEEE Computational Intelligence Magazine.

Forrest, S. et al. (1994). Self-Nonself Discrimination in a Computer, IEEE Symposium on Research in Security and Privacy.

Rabin, S. (2002). AI Game Programming Wisdom, Charles River Media, 1st edition. 